\title{
Erratum to: On comparison of the Earth orientation parameters obtained from different VLBI networks and observing programs
}

\section{Z. Malkin}

Published online: 18 May 2011

(c) Springer-Verlag 2011

Erratum to: J Geod (2009) 83:547-556

DOI: $10.1007 / \mathrm{s} 00190-008-0265-2$

The explanation of Eq. 1 should read:

$\mathbf{r}=r \mathbf{e}_{\mathbf{r}}$ is the baseline vector in terrestrial coordinate system...

The explanation of Eq. 3 should read:

where $r_{e}$ and $r_{p}$ are the equatorial and polar components (projections) of the baseline vector $\mathbf{r}$, respectively...

The online version of the original article can be found under doi:10.1007/s00190-008-0265-2.

Z. Malkin $(\bowtie)$

Central Astronomical Observatory at Pulkovo RAS,

Pulkovskoe Ch. 65, 196140 St. Petersburg, Russia

e-mail: malkin@gao.spb.ru 